\title{
Strategic Game Approach in Multistage Simulation for Supply Chain Planning
}

\author{
Yenming J. Chen \\ Department of Logistics Management \\ National Kaohsiung First Univ. of Sci\&Tech \\ Taiwan
}

\begin{abstract}
This study employs strategic game approach along with multistage simulation to find a supply chain plan in an equilibrium state, in which the configuration design stage and the production dispatching stage hold their coordinated strategies such that no one has incentive to unilaterally change her action, i.e., if a change in strategies by any one of them would lead that player to earn less than if she remained with her current strategy. A mathematical optimization model and a simulation approach are developed in this paper. The study identified a discontinuous relationship between costs and responsiveness through the operational decision of redistribution. Knowing this relationship will allow managers to determine the minimum investment to drive performance improvement and thus, make the best business-level decision at the appropriate moment. When fixed costs are low and facilities increase after game-simulation, capacity efficiency is likewise high regardless of item-simulation.
\end{abstract}

Keywords-stochastic modelling and simulation; strategic games; collaborative systems; business process modelling; service value and supply chains; multistage simulation

\section{INTRODUCTION}

Planning a supply chain usually involves two stages. At the construction stage, the activities focus on configuration design and the resulting production capacity is determined by the scale of investment. At the operation stage, the activities shift to production dispatching and certain slacks between two consecutive tasks are reserved. The decisions on production capacity at stage I and the decisions on schedule slackness at stage II are most likely to be over-estimated in order to absorb unexpected demands or delays. However, the two sets of decisions are not independent. Optimistic estimation to the decisions on production capacity can result to efficient decisions in schedule slackness. Dispatching production activities is relatively safe owing to a sufficiently supported production facility.

This study employs strategic game approach along with multistage simulation to find a supply chain plan in an equilibrium state, in which the configuration design stage and the production dispatching stage hold their coordinated strategies such that no one has incentive to unilaterally change her action, i.e., if a change in strategies by any one of them would lead that player to earn less than if she remained with her current strategy.

Conventional management strategies seek to address the uncertain requirements of customers by building production centers or enhancing the prepared inventory. Therefore, this strategy increases facility costs and the cost of inventories, eroding corporate profits. Overall, increases in storage capacity and inventory at the end can improve the response ability to deliver.

In this research, a novel model is built for analysing capacity efficiency. In this study, the best production centers and an optimal item inventory for all distributors were determined based on the interactive simulation along the game between two parties.

\section{RELATED LITERATURE}

[1] employed a nonlinear model to integrate location and inventory models and successive approximation and algorithm to determine the costs service that production centers must pay in delivering goods to terminal retail outlets. [2] developed an integrated factory site and inventory model. Factory sites, transportation, and the cost of safe inventories were included in the same nonlinear model. Finally, the number of production centers and inventory was determined. [3] believed that although the expansion of facilities could improve response speed, this requires the investment of additional costs.

[4] integrated lead time with ability to create a costeffective and responsive supply chain as a mixed strategy for linking production and logistics. However, the supply chain network that these models investigated did not take into consideration the inventory location assignment of items in the network. This study aims to integrate the previous concept of supply chain with responsiveness and quantitatively analyse the production network model to develop a standard index for making business-level decisions. [5] suggest decisions in a supply chain distribution system should be considered in integration to avoid sub-optimization. Among the facilities location, inventory management, and distribution decisions, any two of the integration are discussed extensively. Please refer to [3] for the location-routing models, [6] and [7] for the inventory-routing models, and [2] and [8] for the locationinventory models.

\section{MODEL}

As shown in Figure 1, the decisionsat the production dispatching stage become constraints to the decisions at the configuration design stage. The interdependent decisions on production capacity and schedule slackness are most likely to be over-estimated in order to absorb unexpected demands or delays. We aim to find a set of decisions that makes the supply chain planning equilibrium. 


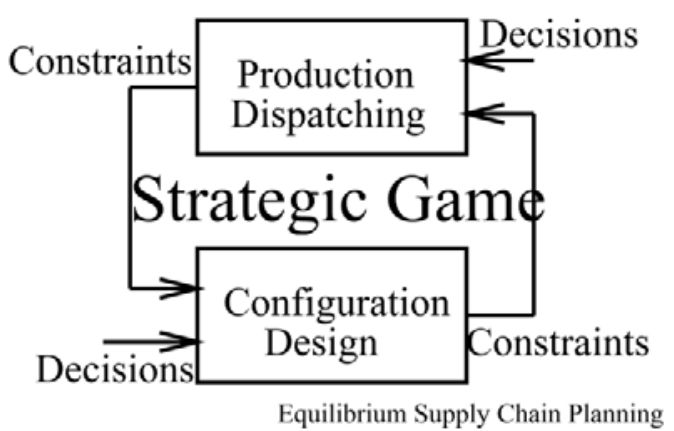

FIGURE I. FRAMEWORK FOR EQUILIBRIUM SUPPLY PLANNING

In the production network, the quantity of the item supply of the productioncenter is considered in the inventory model. Moreover, the limitations of upstream supply are not considered. We also assume that (1) The supply quantity from all distributors in the supply end is known and fixed; and (2) Goods can be replenished either by central or local warehouses.

In our production network, a preliminary program is extended from previous models. Let the binary decisions $\boldsymbol{x}_{\boldsymbol{i}}$ and $\boldsymbol{y}_{i j}$ indicate that if retailer $\boldsymbol{i}$ is selected as a productioncenter and is served from productioncenterj, respectively. Set $\mu_{i}$ and $\sigma_{i}^{2}$ as a yearly demand and variance of daily demand at retaileri, respectively. Whenever open a productioncenter, a fixed cost $f_{i}$ has to be paid. To place an order to productioncenter $\boldsymbol{j}$, there is a fixed $\operatorname{cost} \boldsymbol{F}_{\boldsymbol{j}}$. Let the cost to ship x units of goods from the plant to a regional productioncenter $\boldsymbol{j}$ is $\boldsymbol{v}_{\boldsymbol{j}}(\boldsymbol{x})$ and the cost to ship from retailer $\boldsymbol{j}$ to retailer $\boldsymbol{i}$ is $\boldsymbol{d}_{i j}$. Let $\boldsymbol{\alpha}$ be the desired percentage of retailers orders satisfied, $\boldsymbol{\beta}$ be the weight factor associated with the transportation cost, and $\boldsymbol{\theta}$ be the weight factor associated with the inventory cost. In the statistic production, $\boldsymbol{z}_{\boldsymbol{a}}$ represent the level such that $\operatorname{Pr}\left(\mathbf{z} \leq \mathbf{z}_{\mathbf{a}}\right)=\boldsymbol{\alpha}$. Let $\boldsymbol{h}$ represent the inventory holding cost per unit of product per year and $\boldsymbol{w}_{j}(x)$ be the total annual cost of working inventory held at productioncenter $\mathrm{j}$ if the expected daily demand at $\mathrm{j}$ is $\boldsymbol{x}$. In the stochastic fulfillment cycle, $\boldsymbol{L}$ be the fulfillment lead time. Let the total cost for retailer $\boldsymbol{j}$ is

The program is given as

$$
\begin{gathered}
\min \sum_{j \in D} f_{j} c_{j} x_{j}+\sum_{i \in I} \mu d_{i j} y_{i j}+w_{j}\left(\sum_{i \in I} \mu_{i} y_{i j}\right)+h z_{a} \sqrt{\sigma_{i}^{2} y_{i j}} \\
\text { s.t. } \sum_{j \in D} x_{j} \geq 1, \sum_{j \in D} y_{i j k}=1, \forall{ }_{i} \in C, k \in G \\
y_{i j k}-x_{j} \leq 0, \forall i \in D, j \in C, k \in G \\
\sum_{j \in D} s_{j k}=\sum_{i \in C} u_{i k} \forall k \in G \\
S_{j k} \leq \sum_{i \in c} u_{i k} y_{i j k} \forall j \in D, k \in G
\end{gathered}
$$

$$
\begin{gathered}
s_{j k} \leq A P L_{k} M, \forall i \in D, j \in C, k \in G, \\
x_{i}, y_{i j k} \in\{0,1\}, \forall i, j \in I
\end{gathered}
$$

To build a supply chain production network that is highly efficient, this model employs a location model to determine the location of the productioncenter. Moreover, the model is employed to identify the optimal location of the productioncenter and the optimal allocation of items in the productioncenter, which will allow retailers to select the optimal productioncenter to make replenishment with the maximum profit for the productioncenter.

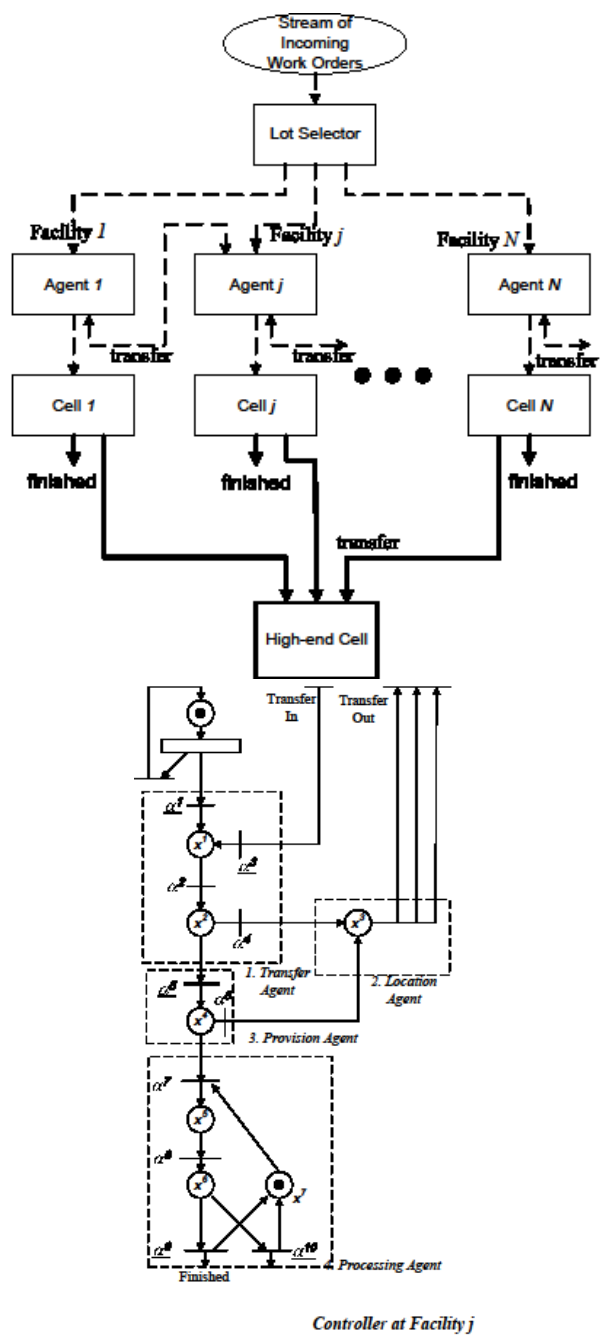

FIGURE II. PRODUCTION DISPATCHING RULE IN THE SIMULATION

The Production dispatching rule in the simulation is illustrated in Fig. 2. Each manufacturing facility takes orders from the lot selector and its agent, in turn, needs to decide to complete this order locally or transfer to other capable manufacturing facilities. For the realistic situation, it is not able to get accurate work load estimation for a manufacture, no matter collectinternally or externally. The control is entirely local and each entity has no real-time and explicit information regarding other parts. Dispatching decisions are thus based upon partialand outdated information. 


\section{ANALYSIS}

At present, the business behaviors of supply chains are generally characterized by low gross benefits, diversified product items with a small quantity, short product life cycle, compliant social responsibility, and large changes in sales. These business behaviors underscore the importance of reducing stock time and improving the turnover rate of inventories. In this regard, an effective production system can improve the service level, maintain environmental sustainability, and promote internal operationefficiency. To enhance responsiveness, order fill rate and continuous supply rate are key factors that should be considered [11]. Given the different lead times between functional and creative products, the lead time of production shouldlikewise be considered, except for the responsiveness to lead time of production. In the scope of the services market of all productioncenters, the delivery of each type of goods to the points that customers need is expected, as well as the quick fulfillment of their order.

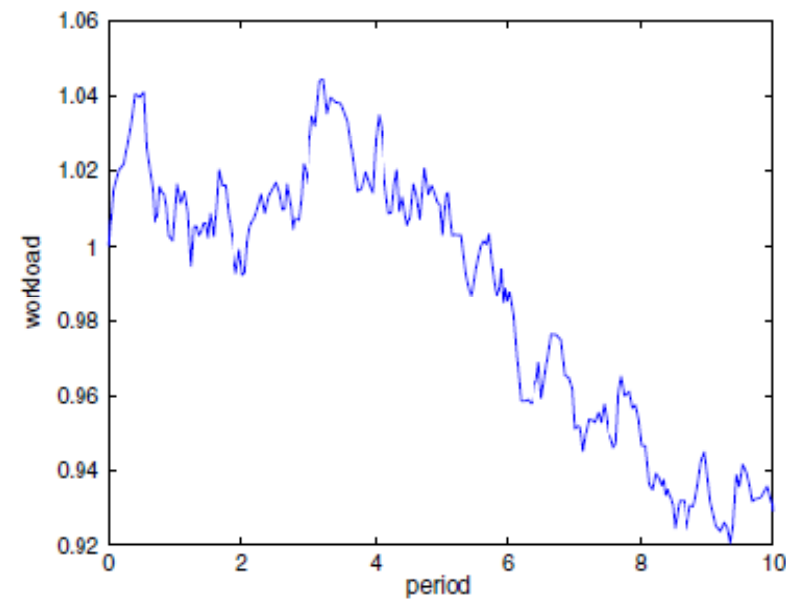

FIGURE III. DEMAND VARIATION WITH POISSON ARRIVAL FOR A SINGLE FACILITY

Figure 4 shows the work load of the manufacturing facility iexhibit a logistic behaviour. The resulting state dependent process is display in Figure 4, given a Poisson arrival. Works arrival decreases due to the saturation of work load.

This proposition data considered the experimental data made by [12] as the discussion verification of the proposition. The productioncenter candidate locations and customer locations in Guangdong Province, China were identified. The experimental data were modified as the materials for this research. This proposition includes 10 retailers and 8 productioncenters. The average service level required by these members is $95 \%$.

\section{CONCLUSIONS}

This paper primarily investigates capacity efficiency and the product features of production centers when enterprises make long-term planning. In addition, this study solves the minimum cost using a mathematical model. First, in terms of the proper ratio between urgent to non-urgent, the advantages of game simulation were confirmed if production responsiveness is better after simulation. Moreover, implementing centralized and decentralized items through game simulation increased the responsiveness of the production center. After simulation, the production center can achieve better responsiveness with reduced cost of inventories. Through simulation, we centralized LAPL items in the production center and decentralized SAPL items in the local production center. Such actions reduced the inventory cost. Observation 3 is similar to the cost of inventories in Observation 2. After simulation, the production center attained better production responsiveness with reduced total cost. Game simulation does not significantly help in improving production responsiveness. Given that game simulation cannot cause large-scale transportation and does not affect cost reduction, greater investment of transport costs cannot result in high responsiveness. When fixed cost is lower and facilities are greater in number, the production responsiveness is the same regardless of game simulation.

In practice, goods will face different demands because of the slack and busy seasons. Therefore, we suggest that the uncertain factors of demand be added in future studies to find solutions that are appropriate for existing states. This paper simplified the cost set, and supposed transport costs were simply related to transport distance. In the industry, transportation with scale economy will reduce the unit cost by increasing transport times. Thus, in future studies, the economic scale of transportation can be considered.

\section{REFERENCES}

[1] S. Erlebacher and R. Meller, "The Interaction of Location and Inventory in Designing Distribution Systems,” IIE Transactions, vol. 32, no. 2, pp. 155-166, 2000.

[2] M. Daskin, C. Coullard, and Z. Shen, "An Inventory-Location Model: Formulation, Solution Algorithm and Computational Results,” Annals of Operations Research, vol. 110, no. 1, pp. 83-106, 2002.

[3] H. Min, V. Jayaraman, and R. Srivastava, "Combined Location-Routing Problems: A Synthesis and Future Research Directions,” European Journal of Operational Research, vol. 108, no. 1, pp. 1-15, 1998.

[4] M. Christopher and D. Towill, "An Integrated Model for the Design of Agile Supply Chains," International Journal of Physical Distribution \& Logistics Management, vol. 31, no. 4, pp. 235-246, 2001.

[5] D. Simchi-Levi, S. Wu, and Z. Shen, Handbook of Quantitative Supply Chain Analysis: Modeling in the E-Business Era, Kluwer, 2004, pp. 138.

[6] A. Kleywegt, V. Nori, and M. Savelsbergh, "The Stochastic Inventory Routing Problem with Direct Deliveries,” Transportation Science, vol. 36, no. 1, pp. 94-118, 2002.

[7] D. Adelman, "A Price-Directed Approach to Stochastic Inventory/Routing," Operations Research, vol. 52, no. 4, pp. 499-514, 2004.

[8] Z. Shen, C. Coullard, and M. Daskin, "A Joint Location-Inventory Model,” Transportation Science, vol. 37, no. 1, pp. 40-55, 2003.

[9] Y. J. Chen and J.-B. Sheu, “Environmental-Regulation Pricing Strategies for Green Supply Chain,” Transportation Research Part E: Logistics and Transportation Review, vol. 45, no. 5, pp. 667-677, 2009.

[10] A. Agarwal, R. Shankar, and M. Tiwari, "Modeling the Metrics of Lean, Agile and Leagile Supply Chain: An Anp-Based Approach,” European Journal of Operational Research, vol. 173, no. 1, pp. 211-225, 2006.

[11] W. Zhuan, Z. Qinghua, and H. Wenwen, “4/r/i/t Distribution Logistics Network 0-1 Programming Model and Application,” Computers \& Industrial Engineering, vol. 55, no. 2, pp. 365-378, 2008. 